\title{
Essay
}

\section{The Benefits of Using Clickers in Small-Enrollment Seminar-Style Biology Courses}

\author{
Michelle K. Smith, ${ }^{*}$ Caleb Trujillo, ${ }^{\dagger}$ and Tin Tin Su
}

\begin{abstract}
Department of Molecular, Cellular and Developmental Biology and Science Education Initiative, University of Colorado, Boulder, CO 80309
\end{abstract}

Submitted September 4, 2010; Accepted October 18, 2010

Monitoring Editor: Eric H. Chudler

\begin{abstract}
Although the use of clickers and peer discussion is becoming common in large-lecture undergraduate biology courses, their use is limited in small-enrollment seminar-style courses. To investigate whether facilitating peer discussion with clickers would add value to a small-enrollment seminar-style course, we evaluated their usefulness in an 11-student Embryology course at the University of Colorado, Boulder. Student performance data, observations of peer discussion, and interviews with students revealed that adding clickers to a small-enrollment course 1) increases the chance students will do the required reading before class, 2) helps the instructor engage all students in the class, and 3) gives students a focused opportunity to share thinking and to learn from their peers.
\end{abstract}

\section{INTRODUCTION}

The utility of clickers and peer discussion in large-lecture introductory biology courses is well established. Typically, instructors pose multiple-choice questions requiring application of a recently presented concept at several points during a class. In one commonly used approach called peer instruction, students first answer a concept question individually, discuss the question with their peers, and then revote before the answer to the question is revealed (Mazur, 1997). The instructor then displays histograms of student responses, which give immediate feedback to both instructors and students on how well a concept is understood.

Several studies have shown that students enjoy using clickers, feel that this form of interactive engagement is useful for their learning, and learn from discussing questions with their

DOI: $10.1187 /$ cbe.10-09-0114

Address correspondence to: Michelle K. Smith (micsmith@ u.washington.edu).

*Present address: Department of Genome Sciences, University of Washington, Seattle, WA 98195.

${ }^{\dagger}$ Present address: Department of Biological Sciences, Purdue University, West Lafayette, IN 47907.

(C) 2011 M. K. Smith et al. CBE—Life Sciences Education (C) 2011 The American Society for Cell Biology. This article is distributed by The American Society for Cell Biology under license from the author(s). It is available to the public under an AttributionNoncommercial-Share Alike 3.0 Unported Creative Commons License (http://creativecommons.org/licenses/by-nc-sa/3.0).

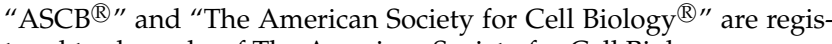
tered trademarks of The American Society for Cell Biology. peers (e.g., Knight and Wood, 2005; Caldwell, 2007; Preszler et al., 2007; Smith et al., 2009). However, despite the evidence about the positive impact of clickers in biology courses, we frequently encounter faculty members who say that there is no benefit to using them in small-enrollment (fewer than 25 students) seminar-style biology courses. When asked why, they commonly say that in small-enrollment courses the instructor already spends a lot of time interacting with students and asking questions. In short, these instructors feel that adding clickers to peer discussion would not add value to the way they teach these types of courses. However, we considered the possibility that clickers offer the additional benefit of instantaneous feedback, while allowing individuals to maintain anonymity. The latter benefit may create a situation that is conducive to encouraging all students to participate in a course, even if it is a small-enrollment course.

To find out if this perception is correct, we investigated adding clickers to peer discussion in an 11-student upperdivision Embryology course at the University of Colorado, Boulder (course demographics in Table 1). Broad learning goals for this course are listed in Table 2. All of the students in this course had experience using clickers in their largeenrollment lower-division biology courses, but this was their first time using clickers in a small-enrollment upper-division biology course.

\section{THE USE OF CLICKERS AND PEER DISCUSSION IN A SMALL-ENROLLMENT COURSE}

In this Embryology course, each student gave two presentations, one on a classic embryology paper chosen by the 
Table 1. Demographic information for students in the Embryology course

\begin{tabular}{ll}
\hline \multicolumn{1}{c}{ Category } & \multicolumn{1}{c}{ Demographic information } \\
\hline Gender & $45 \%$ male, 55\% female \\
Year in college & $18 \%$ junior, 82\% senior \\
Major & $91 \%$ molecular biology, $9 \%$ \\
Grade distribution & biochemistry \\
\hline
\end{tabular}

instructor and another on a recent paper of their choosing. (The distribution of grading points for this course is described in Table 3, and a list of all the papers presented is given in Supplemental Material A). The students prepared PowerPoint slides for use with their presentation and had the option to have it critiqued by the instructor (T.T.S.) ahead of time. The morning before each student's presentation, the instructor added clicker questions to the PowerPoint slides. The students, including the student presenter, did not see the clicker questions ahead of time.

Two types of questions were added to the student presentations. The first type (hereafter called "reading quiz questions") consisted of mostly fact-based questions to determine whether students read the paper before class. An example of a reading quiz question is shown in Figure 1. Students answered these clicker questions individually without peer discussion and received a point only if they got the answer correct. The reading quiz questions were asked throughout the presentation and were designed to cover the key methods and results in the article.

Table 2. Broad learning goals for the Embryology course

At the end of this course, students should be able to explain fundamental embryology experiments and be exposed to current questions in the field. In addition, students should be able to:

Communicate knowledge through writing and speaking.

Explain how experimental evidence is developed.

Apply known methods to new situations.
Prepare a presentation that summarizes findings in a journal article.

Write a grant proposal that has the potential to be funded by an undergraduate granting entity.

Discuss findings from a journal article with their peers.

Interpret and draw conclusions from primary research data, often in graphical and pictorial form. found in journal articles.

Integrate and apply knowledge from previous core biology courses to understanding the techniques used in a journal article.

Distinguish between and justify the use of different possible experimental approaches

Predict the results of future experiments based on information learned in a journal article.

Identify unsolved problems in the field.
Judge the validity of conclusions
Table 3. Distribution of grading points in the Embryology course

\begin{tabular}{lc}
\hline & Percent \\
\hline Clicker questions (reading quiz and application & 30 \\
$\quad$ questions) & 15 \\
Oral presentation I & 15 \\
Oral presentation II & 5 \\
Asking questions during presentations & 10 \\
$\quad$ (participation points) & 20 \\
Grant proposal draft & 5 \\
Final grant proposal & \\
\hline
\end{tabular}

The second question type (hereafter called "application questions") asked students to apply what they learned from the paper and presentation. An example of an application question is shown in Figure 2. The application questions were asked at the end of the presentation. Students answered the application questions individually, discussed the answer with their peers, and then answered the same question again. The histograms of student responses were not revealed to students until after they answered the questions a second time, because when class responses to clicker questions are shown, students are inclined to move to the most common answer, which likely diminishes the value of peer discussion (Perez et al., 2010). Students received participation points regardless of their answers for the application questions. Participation points were awarded for these types of questions because the instructor wanted to emphasize discussion, scientific argument, and articulation of thought over just getting the right answer. A typical presentation included four reading quiz questions and two application questions.

During the class, students and the instructor sat around a single large table. For the peer-discussion portion of the application questions, our observations revealed that the 11 students tended to divide into two groups based on where they were sitting. A typical discussion would begin with one student saying what he or she answered and then the other students in the group would say if they agreed or disagreed with the answer. Even if students all agreed on a particular answer, they would often discuss why the other answers were incorrect. A transcript of a student discussion is given in Supplemental Material B. The instructor removed herself from the peer discussion as much as possible and would ask clarifying questions only if the students started to go off track with their discussion.

\section{The mtmr8 gene encodes: \\ A. a kinase \\ B. a receptor \\ C. a phosphatase \\ D. a transcription factor \\ E. none of the above}

Figure 1. Example of a reading quiz question from a paper by Mei et al. (2009). The correct answer is underlined. 


\section{Based on the model in Figure 8, which of these manipulations have the potential to relieve muscle defects in Mtmr8-depleted fish embryos?}

\section{A. Making a mutant Akt that mimics constitutive/elevated phosphorylation \\ B. Elevating PI3K levels or activity \\ C. Increasing Hh levels/activity \\ D. Making a depletion/loss of function mutation in Nexilin \\ E. Either B or C}

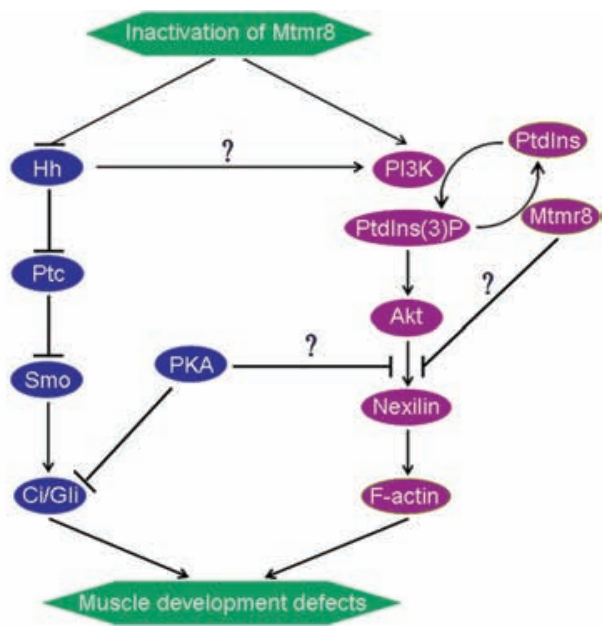

Figure 2. Example of an application question from a paper by Mei et al. (2009). The correct answer is underlined.

\section{STUDENT REACTIONS TO USING CLICKERS IN A SMALL-ENROLLMENT COURSE}

In addition to examining student performance results and observing peer discussion, a researcher not associated with the course (M.K.S.) interviewed 8 of the 11 students about their experience using clickers in this small-enrollment course. The interview results revealed that clickers added value to this embryology course in three important ways.

First, all of the interviewed students stated that adding clicker questions to the student presentations encouraged them to read the papers before class. As one student admitted, "I doubt I would have read the papers if there were no clicker questions, or at least I would have tried to get by without reading them." The average score on the individually answered reading quiz questions was $69 \%$ (SEM $=3.21 \%, n$ $=79$ questions). Although that may not seem impressive at first, some studies have shown that only $20-30 \%$ of the students read assignments before class when requested by their instructor (reviewed by Hobson, 2004). Also, several students felt that the way they read scientific papers improved because of the clicker questions. For example, one student said: "As I am reading the paper I think, what will Tin Tin ask about? It forces me to think about the organism used, the type of experiment, etc."

Of course, there are other ways to encourage students to read papers before class. During the previous five times teaching this class, the instructor used preclass reading quizzes, which consisted of factual questions only. However, the instructor observed that, even if students read the paper and were able to answer quiz questions correctly, they often tuned out the subsequent student presentation. In dispersing the reading quiz questions throughout the presentation with the facilitation of clickers, the instructor hypothesized that students would remain more engaged. During the interviews, seven of the eight students commented that having the clicker questions helped them pay attention to the student presentations. According to one student: "I would still read the papers in other classes but for this class I highlight key things and keep the paper open while the presentation is going on, so I can keep track of what is going on."
Second, students felt that asking clicker questions creates an environment where every student, not just one or two, thinks through and answers each question being asked. In many small-enrollment biology courses, instructors ask openended questions and call on a student to answer. However, even with such efforts, there is potential for the remaining students to be left out of the discussion, especially if they are not confident about the answer. During the interviews, students talked about how they liked contributing to the class even when they were not speaking. Three such descriptions follow:

If we didn't have clicker questions then 2-3 people would dominate the conversation and Tin Tin might think because they understand what is going on, we all understand it. Clickers give people a voice, even if it is not a verbal one.

If you didn't have clickers and Tin Tin asked openended questions to us, most of the time I would just think: "well I do not know" and just sit there and listen to what she says is correct.

Clickers force students to answer and discuss. You avoid that blank stare after the instructor asks you to answer questions. They get students thinking and their brains moving.

Finally, the application questions gave students an opportunity to articulate their thinking and learn from their peers during class. When students voted individually on the application questions, the average percent correct equaled $53.9 \%$ (SEM $\pm 4.6, n=22$ questions). But after peer discussion, the average percent correct increased to $91.5 \%(\mathrm{SEM} \pm 3.7)$. Therefore, just as has been reported in large-enrollment biology courses (e.g., Knight and Wood, 2005; Smith et al., 2009), peer discussion in small-enrollment courses also improves student performance on clicker questions. One student described the peer discussion experience this way: "It is like going to a coffee shop and talking about science over coffee. I like hearing what my classmates think and they often bring up something I didn't think of. We work together as a whole to figure out the answer." 
While all eight of the students we interviewed thought that clickers were a useful learning tool in small-enrollment courses, five of the eight students mentioned suggestions for improving their use. First, students wanted to have meet-andgreet time during the first week of class, so they could feel more comfortable talking with each other. Second, students expressed that they wanted a chance to write some of their own clicker questions. They thought that writing a subset of the clicker questions sounded like a lot of fun and would help them organize their presentation.

\section{CONCLUSIONS}

The performance, observation, and interview data provide encouraging information for instructors who are considering using clickers in their small-enrollment seminar-style biology courses. Importantly, adding clicker use to peer discussion enhanced a small-enrollment biology course by increasing the chance students will read before class, helping the instructor engage all students, and giving students a focused opportunity to share thinking and to learn from their peers. There are many future research questions that can be asked regarding the use of clickers in small-enrollment settings. For example, do students who have not used clickers in previous courses find that clickers are an effective tool in a small lecture setting? Are there other small-enrollment settings such as laboratory meetings and departmental seminars where clickers could be an effective tool for engaging the audience? For instructors interested in including in-class concept questions in their courses, several resources are available at http:/ /STEMclickers.colorado.edu.

\section{INSTITUTIONAL REVIEW BOARD (IRB) PROTOCOLS}

Approval to evaluate student clicker responses (exempt status, Protocol No. 0108.9) and interview students (expedited status, Protocol No. 0603.08) was granted by the Institutional Review Board, University of Colorado, Boulder.

\section{ACKNOWLEDGMENTS}

We thank the Science Education Initiative at the University of Colorado, Boulder, for full support of M.K.S. and partial support of C.T. We also thank Jenny Knight, Carl Wieman, and Kathy Perkins for intellectual support and Bill Wood for his comments on the manuscript.

\section{REFERENCES}

Caldwell JE (2007). Clickers in the large classroom: current research and best-practice tips. CBE Life Sci Educ 6, 9-20.

Hobson EH (2004). Getting Students to Read: Fourteen Tips. IDEA PAPER \#40. The Excellence in Teaching Center, Georgia Southern University.

Knight JK, Wood WB (2005). Teaching more by lecturing less. CBE Life Sci Educ 4, 298-310.

Mazur E (1997). Peer Instruction: A User's Manual, Upper Saddle River, NJ: Prentice Hall.

Mei J, Li Z, Gui JF (2009). Cooperation of Mtmr8 with PI3K regulates actin filament modeling and muscle development in zebrafish. PLoS One 4, e4979.

Perez KE, Strauss EA, Downey N, Gabraith A, Jeanne R, Cooper $S$ (2010). Does displaying the class results affect student discussion during peer instruction? CBE Life Sci Educ 9, 133-140.

Preszler RW, Dawe A, Shuster CB, Shuster M (2007). Assessment of the effects of student response systems on student learning and attitudes over a broad range of biology courses. CBE Life Sci Educ 6, $29-41$.

Smith MK, Wood WB, Adams WK, Wieman C, Knight JK, Guild N, $\mathrm{Su}$ TT (2009). Why peer discussion improves student performance on in-class concept questions. Science 323, 122-124. 